\title{
The influence of potassium on the weathering properties of kimberlite and the information provided by different testing methods
}

\author{
Jacqueline Morkel $^{\mathrm{a}}$ and Serkan Saydam ${ }^{\mathrm{b}}$ \\ ${ }^{\mathrm{a}}$ Department of Materials Science and Metallurgical Engineering, University of \\ Pretoria, Pretoria, South Africa \\ ${ }^{\mathrm{b}}$ School of Mining Engineering, The University of New South Wales, Sydney, NSW, \\ Australia
}

\section{Article Outline}

1. Introduction

2. Experimental work, results and discussion

2.1. Material

2.2. Particle size distribution

2.3. Slake durability index test

2.4. Brazilian tensile strength test

2.5. Uniaxial compressive strength test

2.6. Swelling tests

2.7. Geodurability classification

2.8. XRD interlayer spacing

2.9. Adhesion strength tests

3. Conclusions and recommendations

Acknowledgements

References

\section{Introduction}

Kimberlites are described as ultrabasic igneous rocks that occur as volcanic pipes, dykes and sills [1]. The minerals and mineral groups present in kimberlites vary widely and can include from trace to predominance any of the following minerals or mineral groups: apatite, calcite, chlorite, diopside (pyroxene), feldspar, magnetite, monticellite, olivine, phlogopite (mica), perovskite, quartz, serpentine, smectite and talc. It has been shown that kimberlite is prone to weathering when smectite minerals are present [2] and that weathering correlates with the abundance of smectite. Cation exchange takes place in smectites and changes the mechanical properties of the kimberlite [3], [4], [5] and [6]. $\mathrm{K}^{+}$ is one of the few cations that collapse the swelling clay interlayer of smectites [7], [8] and [9]. The collapsing capability of $\mathrm{K}^{+}$in smectite minerals is investigated in this paper to evaluate the effect on the mechanical properties of kimberlite This paper furthermore investigates different tests for evaluating the degradation properties of kimberlite. 


\section{Experimental work, results and discussion}

\subsection{Material}

For this study, kimberlite samples were obtained from the Venetia, Dutoitspan and Cullinan Diamond Mines of De Beers Consolidated Mines in South Africa. A sample of Red Kimberlite was obtained from Venetia Diamond Mine, while Dutoitspan provided a Tuffisitic Kimberlite Breccia (TKB). Two TKB kimberlites were collected from Cullinan Diamond Mine from Level 717, Tunnel (T)24 and T66N (north). The kimberlites are named Venetia Red, Dutoitspan, Cullinan T24 and Cullinan T66N. The samples were received as large blocks $20-30 \mathrm{~cm}$ in length and width, and $15 \mathrm{~cm}$ high. Samples were prepared according to the requirements for each testing method. Mineralogical characterisation of these kimberlites was conducted utilising XRD to confirm the presence and abundance of smectite.

\subsection{Particle size distribution}

A particle size distribution (PSD) before and after a weathering test could give an indication of the extent of weathering/degradation that took place. For this test a $1.5 \mathrm{~kg}$ Dutoitspan kimberlite sample (lumps) was sized in the $-16+13.2 \mathrm{~mm}$ size fraction after crushing. This sample was exposed to distilled water and a $0.05 \mathrm{M}$ potassium chloride $(\mathrm{KCl})$ solution for six days. Tests were performed at room temperature in $10 \mathrm{~L}$ flatbottomed plastic containers using $5 \mathrm{~L}$ solution. The particles were spread as a single layer, not touching and no dispersion took place. The weathered samples were removed from the water/medium after the weathering period and left to air dry for one day. The dried sample was sieved and a PSD curve obtained.

The PSD for the distilled water and $0.05 \mathrm{M} \mathrm{KCl}$ solutions are shown in Fig. 1. For comparative purposes the PSD curve can be cut at a constant sieve size to report a single data point as output. The cumulative \% passing at $10.3 \mathrm{~mm}$ is $20.8 \%$ in the distilled water compared to $7.5 \%$ in the potassium $\left(\mathrm{K}^{+}\right)$solution. $\mathrm{K}^{+}$shows an inhibiting effect on kimberlite weathering, which can be demonstrated by a PSD. The output of a PSD is complicated, as it is a data series instead of a single value. The other disadvantage of this method is that different kimberlite types will not be comparable if different particle sizes are used. This is an easy and inexpensive test, which can be done in-house rather than utilising commercial laboratories. This specific test was performed in six days, but the time can be reduced in some instances. The other advantage of this test is that it can be adapted to fit the specific requirements. 


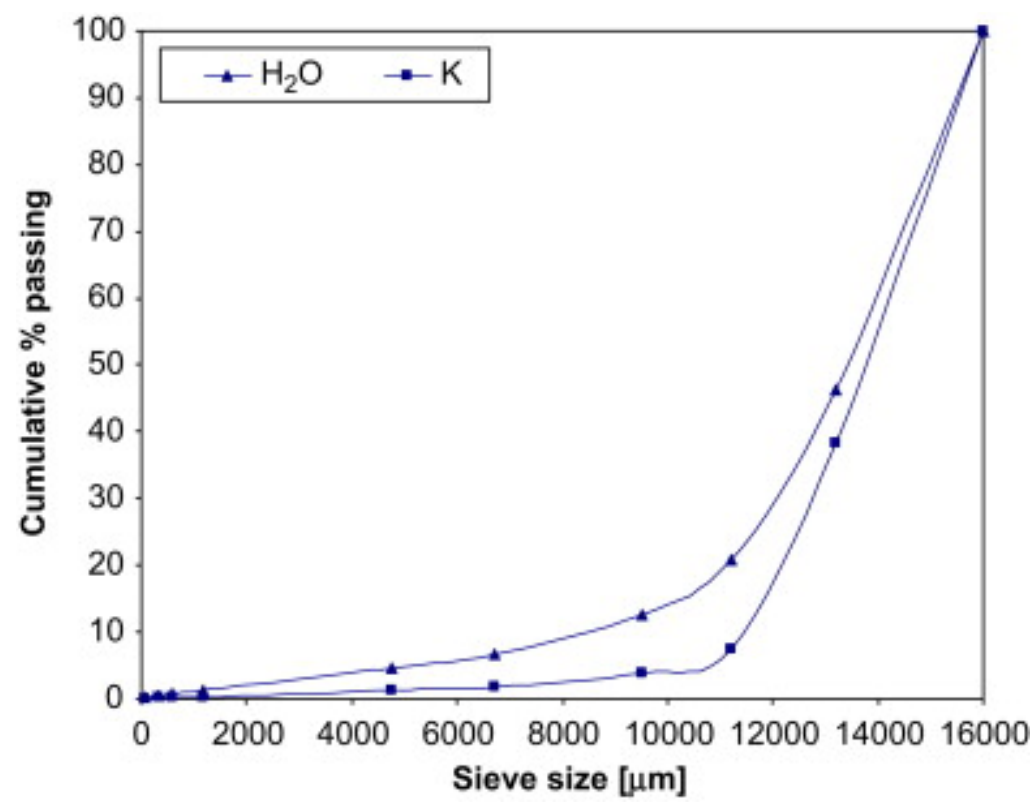

Fig. 1. The particle size distribution for a $1.5 \mathrm{~kg}$ Dutoitspan kimberlite sample $(-16+13.2 \mathrm{~mm})$ weathered in distilled water and a $0.05 \mathrm{M} \mathrm{KCl}$ solution for 6 days.

\subsection{Slake durability index test}

The slake durability index (SDI) test combines the effect of cyclic swelling and abrasion to accelerate the rate of weathering, which enables measuring the resistance of the rock to physical, mechanical and (to some extent) chemical weathering. A study by Gökçeoglu et al. [10] found a correlation between the SDI of the clay bearing rocks and the expandable clay minerals. This indicates possible correlation between kimberlite weathering and SDI since smectite (expandable clay) determines kimberlite weathering [2].

This test was standardised by the American Society for Testing and Materials (ASTM D4644-04). The sample is rotated in a steel mesh drum partially immersed in water for $10 \mathrm{~min}$ ( $\sim 200$ rotations); with oven drying for $8-12 \mathrm{~h}$ at $\sim 80^{\circ} \mathrm{C}$ between slake cycles. These steel drums are made of sieve mesh of $2 \mathrm{~mm}$, allowing all particles smaller than this to pass into the water bath. The SDI is defined as the percentage of the final weight $(>2 \mathrm{~mm})$ compared to the initial dry weight [10]. SDI values are normally categorised (see Table 1) to provide a simple weatherability classification for ores. 
Table 1.

Defining the slake durability index values

\begin{tabular}{|l|l|}
\hline Amount of slaking & Slake durability index (\%) \\
\hline Very low & $0-25$ \\
\hline Low & $25-50$ \\
\hline Medium & $50-75$ \\
\hline High & $75-95$ \\
\hline Very high & $95-100$ \\
\hline
\end{tabular}

The SDI test unit utilised for test work is located at the De Beers Ground Support Laboratory in Johannesburg, South Africa. The kimberlite samples were crushed to pieces in the order of $3 \mathrm{~cm}$ and 400-600 g utilised per test. Venetia Red kimberlite was exposed to the SDI test in distilled water and a $1.0 \mathrm{M} \mathrm{KCl}$ solution whilst Cullinan T24 and $\mathrm{T} 66 \mathrm{~N}$ samples were exposed to distilled water and a $1.5 \mathrm{M} \mathrm{KCl}$ solution. These tests utilised four cycles, drying for 1 day at $80^{\circ} \mathrm{C}$ between each cycle and reporting the weight loss during each cycle.

The SDI results are shown in Fig. 2. The SDI of Venetia Red kimberlite was improved from $\sim 5 \%$ to $20 \%$ with the addition of $\mathrm{K}^{+}$to the test solution (after the fourth cycle). SDI results for Cullinan T24 kimberlite was improved from $\sim 48 \%$ to $86 \%$, and Cullinan T66N was improved from $\sim 74 \%$ to $92 \%$ in the presence of $\mathrm{K}^{+}$cations.

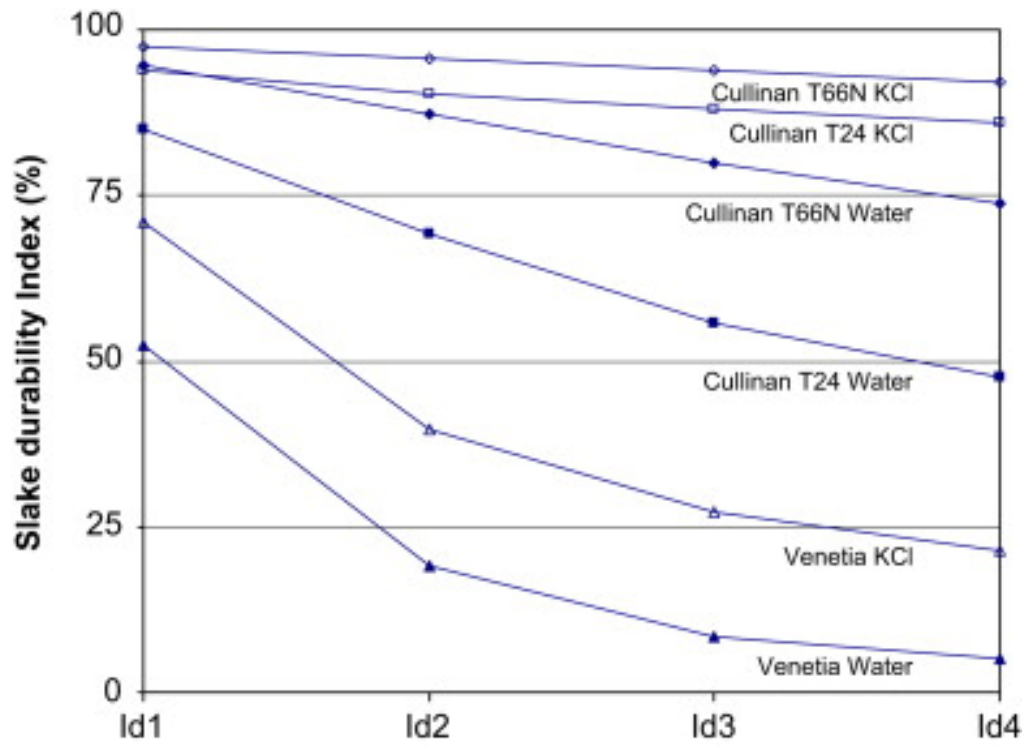

Fig. 2. Slake durability index test results for Venetia Red, Cullinan T24 and Cullinan $\mathrm{T} 66 \mathrm{~N}$ in distilled water and a $\mathrm{KCl}$ solution. 
The SDI test was also utilised to investigate the influence of $\mathrm{K}^{+}$concentration, results are shown in Fig. 3. The SDI of Venetia Red kimberlite was improved from 5\% to $19 \%$ in a $0.5 \mathrm{M} \mathrm{K}^{+}$solution, and to $22 \%$ in a $1 \mathrm{M} \mathrm{K}^{+}$solution. Increasing the $\mathrm{K}^{+}$concentration improved slaking behaviour in this case. The Cullinan T24 SDI result is the same for both concentrations with an increase of $\sim 40 \%$ compared to distilled water.

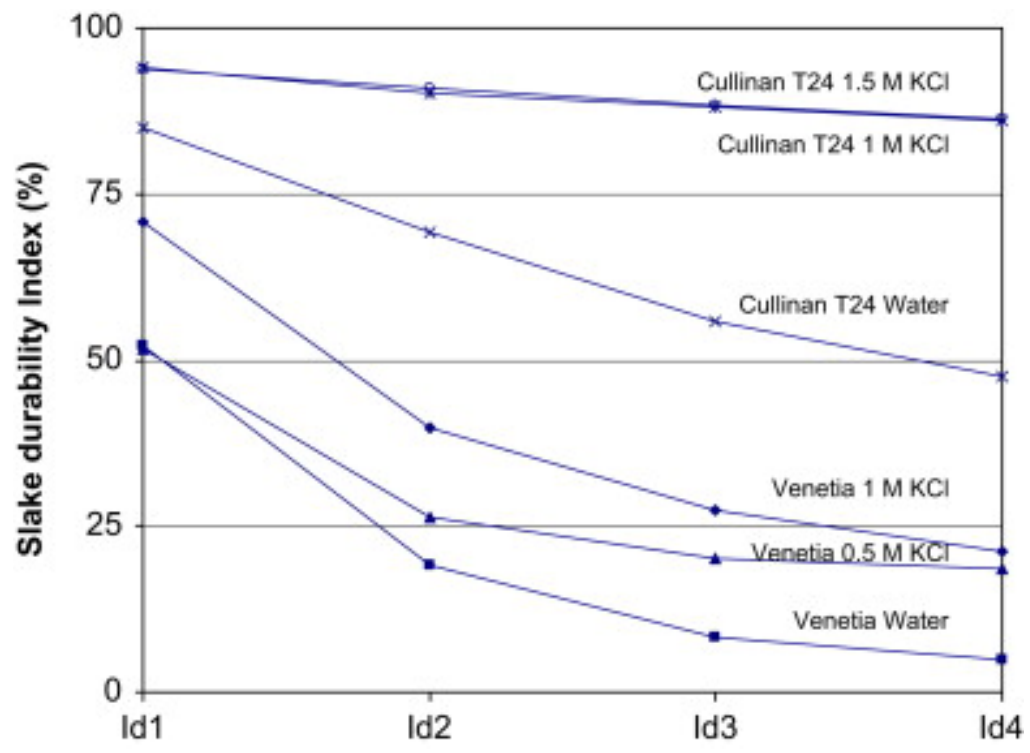

Fig. 3. SDI test results for Venetia Red in distilled water, a $0.5 \mathrm{M} \mathrm{KCl}$ solution and a $1 \mathrm{M}$ $\mathrm{KCl}$ solution. The slake durability test results for Cullinan T24 in distilled water and a 1 and $1.5 \mathrm{M} \mathrm{KCl}$ solution are also shown.

The SDI test can evaluate kimberlite weathering and is an easy and cost effective test. It does, however, take a few days to perform due to wetting and drying cycles.

\subsection{Brazilian tensile strength test}

The Brazilian tensile strength (UTB) test is intended to measure the uniaxial tensile strength of a rock indirectly. This test is based on the fact that most rocks in biaxial stress fields will fail in tension when one principal stress is compressive and the other tensile. The apparatus consists of two jaws that contact the disc-shaped rock sample at diametrically opposed surfaces. A description of the ASTM test conditions is given by the International Society for Rock Mechanics [11].

The UTB test was conducted with Cullinan T66N kimberlite core samples, weighing 80$100 \mathrm{~g}$ each with a diameter of $\sim 43 \mathrm{~mm}$ and a height of $\sim 20 \mathrm{~mm}$. These tests were performed at the Soillab in Pretoria, South Africa. Tests were conducted on specimens exposed to air, submerged in distilled water for $20 \mathrm{~min}$ and submerged in a $1.5 \mathrm{M} \mathrm{KCl}$ solution for $20 \mathrm{~min}$. After the treatments the drill core specimens were air dried for $24 \mathrm{~h}$ before conducting the UTB test. Results are reported as the average of four 
measurements. Samples could not be exposed to water for longer time periods as it failed and could not be exposed to the UTB test.

The untreated T66N samples report an average UTB of 7.9 MPa, the water treated samples measured $7 \mathrm{MPa}$ and the $\mathrm{K}^{+}$treated samples $8.9 \mathrm{MPa}$ (Fig. 4). An experimental error range of $\pm 0.6 \mathrm{MPa}$ was established. The tensile strength test does not seem to be a very useful technique in determining the weatherability of a kimberlite.

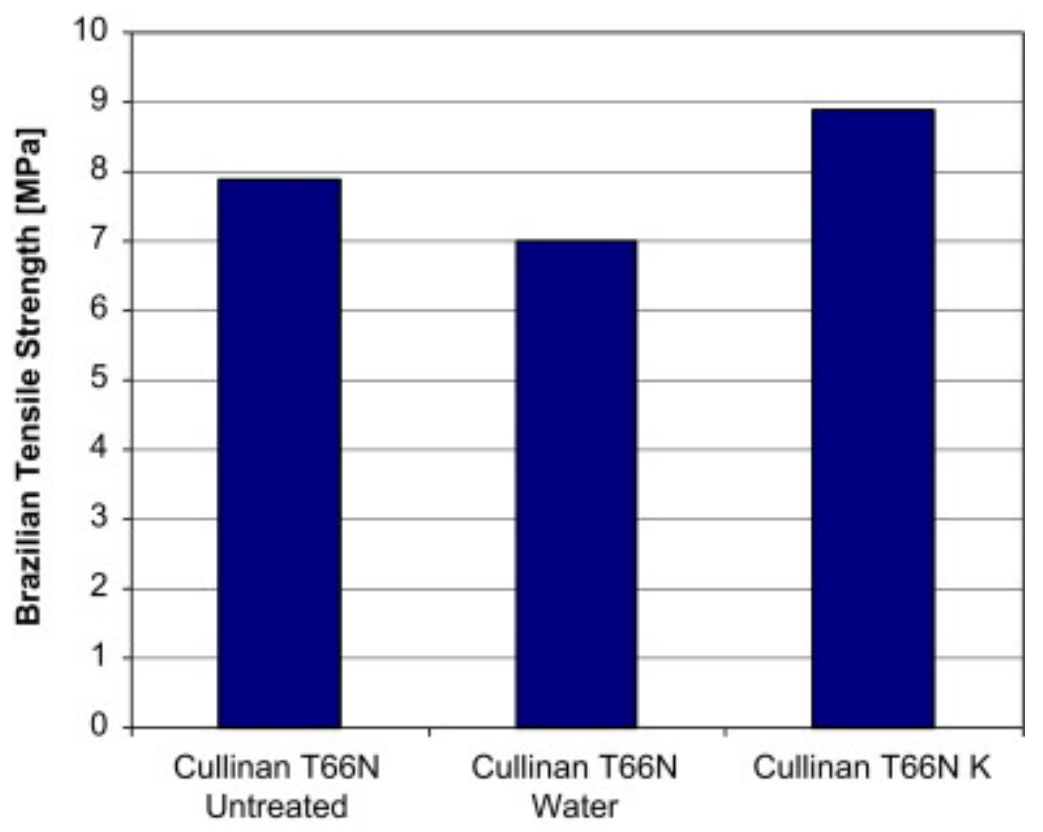

Fig. 4. UTB test results for Cullinan T66N for the untreated, water treated and $1.5 \mathrm{M} \mathrm{KCl}$ treated environments. Treatment occurred by submerging the cores in the distilled water and $\mathrm{K}^{+}$solution for $20 \mathrm{~min}$ before drying for $24 \mathrm{~h}$.

\subsection{Uniaxial compressive strength test}

The uniaxial compressive strength (UCS) is a frequently applied test for measuring the strength of rocks and is performed according to specifications documented by the International Society for Rock Mechanics [11].

UCS tests were conducted with Cullinan T66N kimberlite core samples with a diameter of $43 \mathrm{~mm}$, a height of 60-80 $\mathrm{mm}$ and each sample weighing 250-300 g. These tests were done at the Soillab too. Specimens were exposed to air, submerged in distilled water for $30 \mathrm{~min}$ and submerged in a $1.5 \mathrm{M} \mathrm{KCl}$ solution for thirty minutes before air drying for eighteen hours and conducting the UCS test. An average of five drill cores was used for each measurement. These specimens could also not be exposed to water for longer time periods as the specimens started cracking and failing and could not be used to test UCS. 
The untreated Cullinan T66N samples reported a strength of $54 \mathrm{MPa}$, the water treated samples measured $47 \mathrm{MPa}$ and the $\mathrm{K}^{+}$treated samples $57 \mathrm{MPa}$ (Fig. 5). The error range was found to be $\pm 10 \mathrm{MPa}$ and therefore the UCS does not show a significant difference between the air, water and $\mathrm{K}^{+}$treated samples. The UCS similar to the UTB test does not seem to be a suitable weathering classification test.

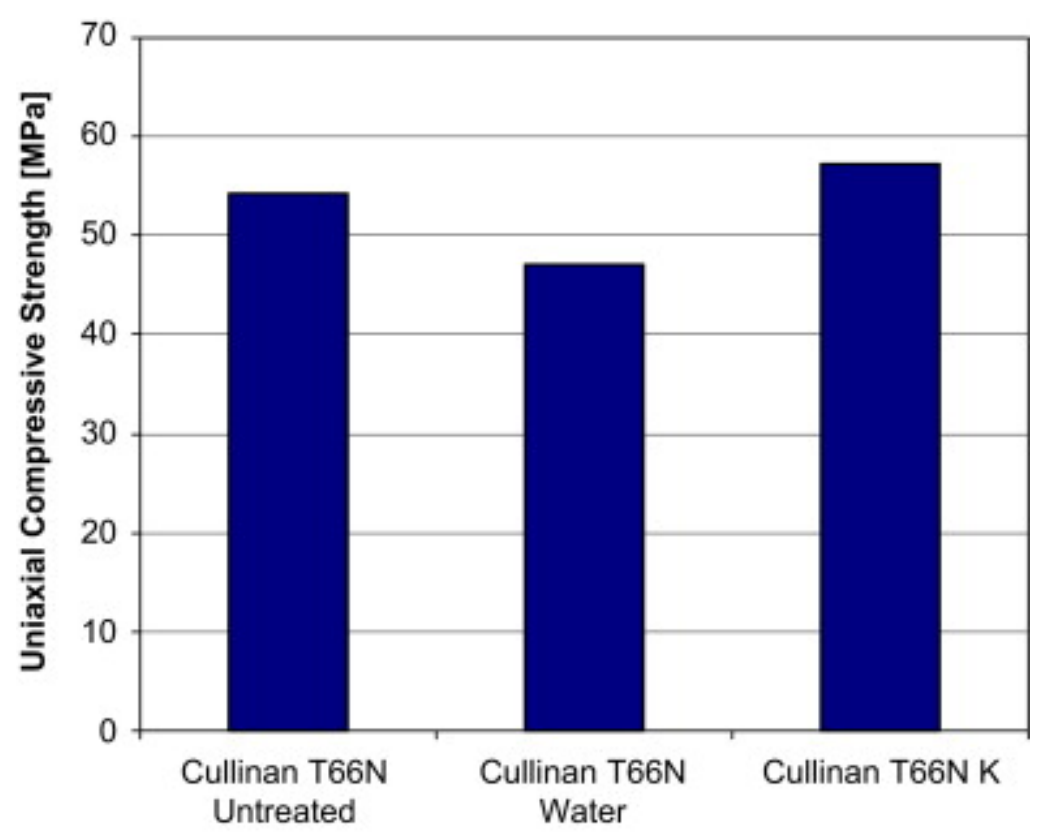

Fig. 5. UCS results for Cullinan T66N in the untreated, water treated and $1.5 \mathrm{M} \mathrm{KCl}$ treated conditions. Treatment of the drill core specimens was conducted by submersion in the medium for $30 \mathrm{~min}$ before drying for $18 \mathrm{~h}$.

\subsection{Swelling tests}

A review of the different methods of testing swelling is given by Madsen [12]. A drill core specimen of very specific dimensions is usually required for each testing unit. The Duncan Free Swelling Test [13] measures the swelling displacement in the central axis of the specimen as a function of time. It is carried out by submerging the entire core in distilled water or another applicable medium and then monitoring the change in length up to the maximum point, by means of a dial gauge placed at the top of the specimen.

Results from these tests are given as $\Delta L$ (change in length) $/ L$ (original length) either as a fraction or percentage at a specific time.

Swelling tests were conducted by the Soillab and utilised Cullinan T66N kimberlite cores of a $43 \mathrm{~mm}$ diameter, $40 \mathrm{~mm}$ in height and weighing $\sim 150 \mathrm{~g}$. An average of five drill core specimens was exposed to the swelling test in both distilled water and $1.5 \mathrm{M} \mathrm{KCl}$ solution. The axial swelling was reported at 12 and 24 h, as shown in Fig. 6. 


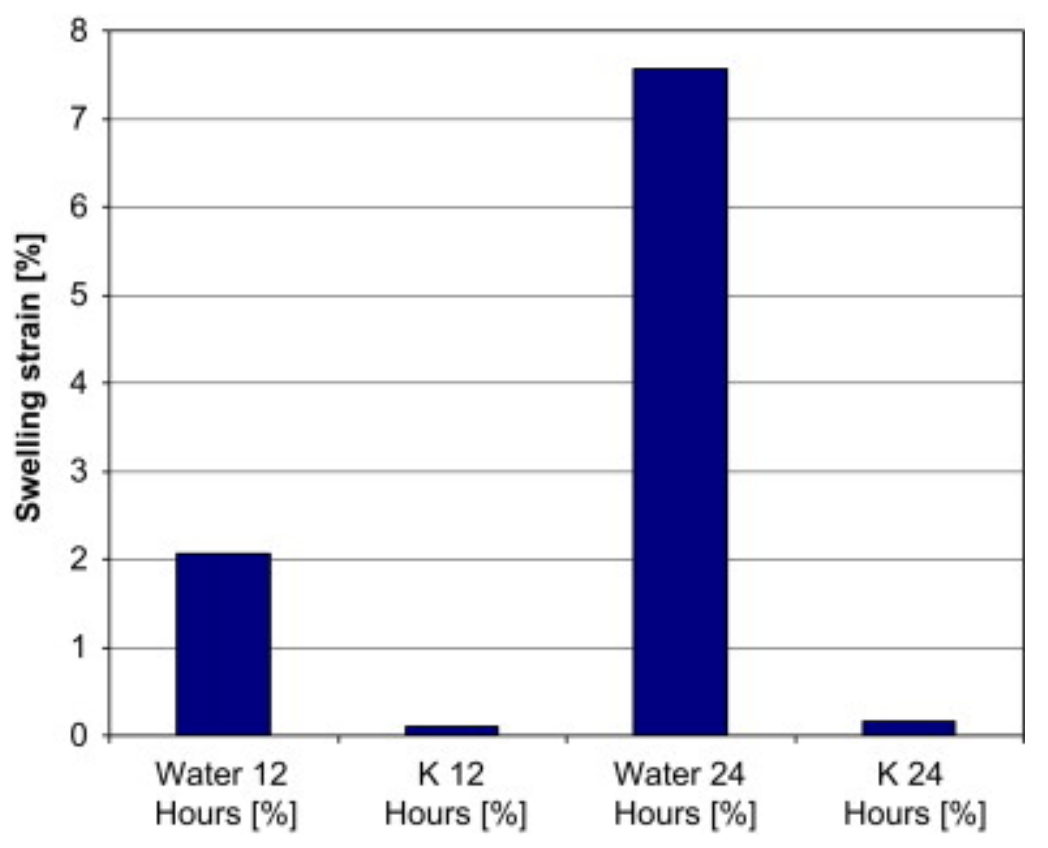

Fig. 6. Duncan Free Swelling of Cullinan T66N in distilled water and a $1.5 \mathrm{M} \mathrm{KCl}$ solution.

The average swelling strain was $2 \%$ at $12 \mathrm{~h}$ exposure to water, which increased to $7.6 \%$ after $24 \mathrm{~h}$, while the $\mathrm{KCl}$ medium yields a swelling strain of $0.1 \%$ at $12 \mathrm{~h}$ and $0.16 \%$ at $24 \mathrm{~h}$. Although the error range in swelling strain measurements are very large, the difference in swelling strain in water and the $\mathrm{K}^{+}$medium is large enough to provide significant information and therefore the swelling test can be considered a suitable test for kimberlite weathering studies.

\subsection{Geodurability classification}

The geodurability classification developed by Olivier [13] combines the UCS and Duncan Free Swelling coefficient into a new rock classification. The rock material is classified into one of five classes from 'excellent' (class A) to 'very poor' (class E). In that work the technique was found to be especially applicable to compacted and weakly cemented rocks, where the rock material deteriorates with time.

The geodurability classification results are shown in Fig. 7, which classified the Cullinan T66N kimberlite as 'very poor' in distilled water compared to a 'good' classification with a $\mathrm{K}^{+}$medium. The geodurability classification seems to be an appropriate representation of the weatherability of kimberlites, although the swelling strain coefficient is the parameter that predominantly provides the information. This technique enables quantification of the effect of $\mathrm{K}^{+}$cations on kimberlite weathering. 


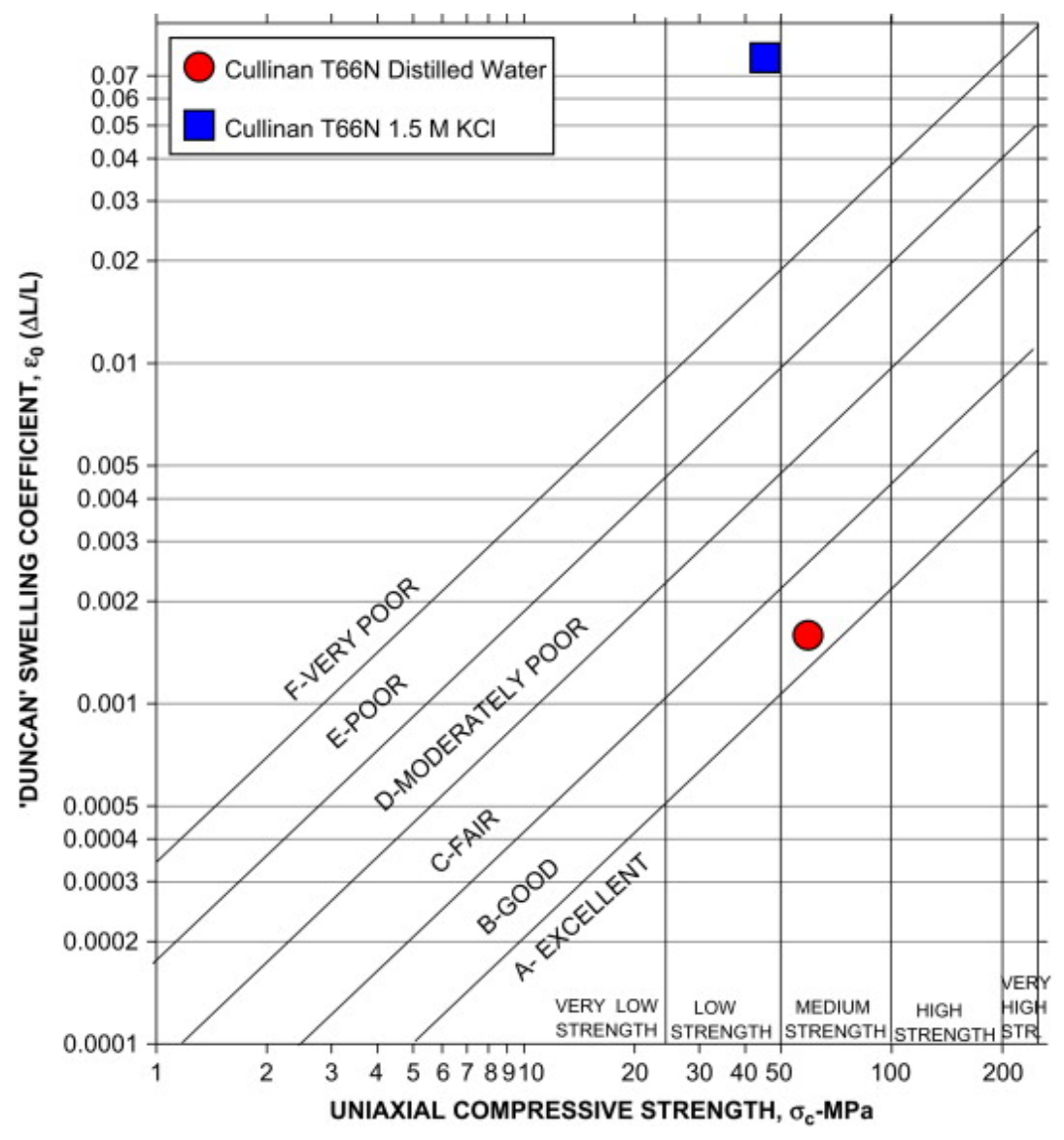

Fig. 7. Geodurability classification for Cullinan $\mathrm{T} 66 \mathrm{~N}$ in distilled water and a $1.5 \mathrm{M} \mathrm{KCl}$ solution.

\subsection{XRD interlayer spacing}

The amount of smectite present in a rock sample can be determined by XRD, and this was shown to correlate with the degree of weathering of that rock [2]. The XRD smectite interlayer spacing (d-spacing at the 001 peak position) has been used by other studies to indicate the extent of swelling [14]. An interlayer spacing below $10 \AA$ is associated with 0 water layer, $12.6 \AA$ with 1 water layer, $15.6 \AA$ with 2 layers, $18.6 \AA$ with 3 layers, $21.6 \AA$ with 4 layers and above that with more water layers [15]. The collapsing capability of $\mathrm{K}^{+}$was studied by Malla and Douglas [16], which showed that the smectite interlayer could be collapsed to 10.6-12.8 $\AA$ depending on the layer charge of the original smectite layer. Carson and Dixon [9] showed collapse of calcium montmorillonite from 23 to $14 \AA$ with $\mathrm{K}^{+}$. Ferrage et al. [17] showed that under ambient conditions $\mathrm{K}^{+}$ exchanged montmorillonite results in predominantly 0 water layer.

The XRD smectite interlayer spacing was investigated utilising Venetia Red kimberlite milled to a fine powder and conducted at the University of Pretoria on a Siemens D501 with copper and cobalt lamps at a $4-70^{\circ} 2 \theta$ range. The untreated Venetia Red kimberlite XRD spectrum was compared to a sample exposed to a $1.5 \mathrm{M} \mathrm{KCl}$ solution for $4 \mathrm{~h}$. 
The results for the untreated and $\mathrm{KCl}$ treated Venetia Red kimberlite are shown in Fig. 8. An interlayer spacing of $14 \AA$ was measured in the untreated kimberlite compared to a $12.5 \AA$ interlayer spacing in the $\mathrm{K}^{+}$treated sample. This confirms the collapsing capability of $\mathrm{K}^{+}$cations of the smectite interlayer, which in turn influences the weathering properties of the kimberlites. Although this test will identify the presence, quantity and swelling state of smectite present in a kimberlite (which can be used to predict the weatherability), it does not provide a direct quantitative measurement of the weathering and will not be as useful as a direct weathering test.

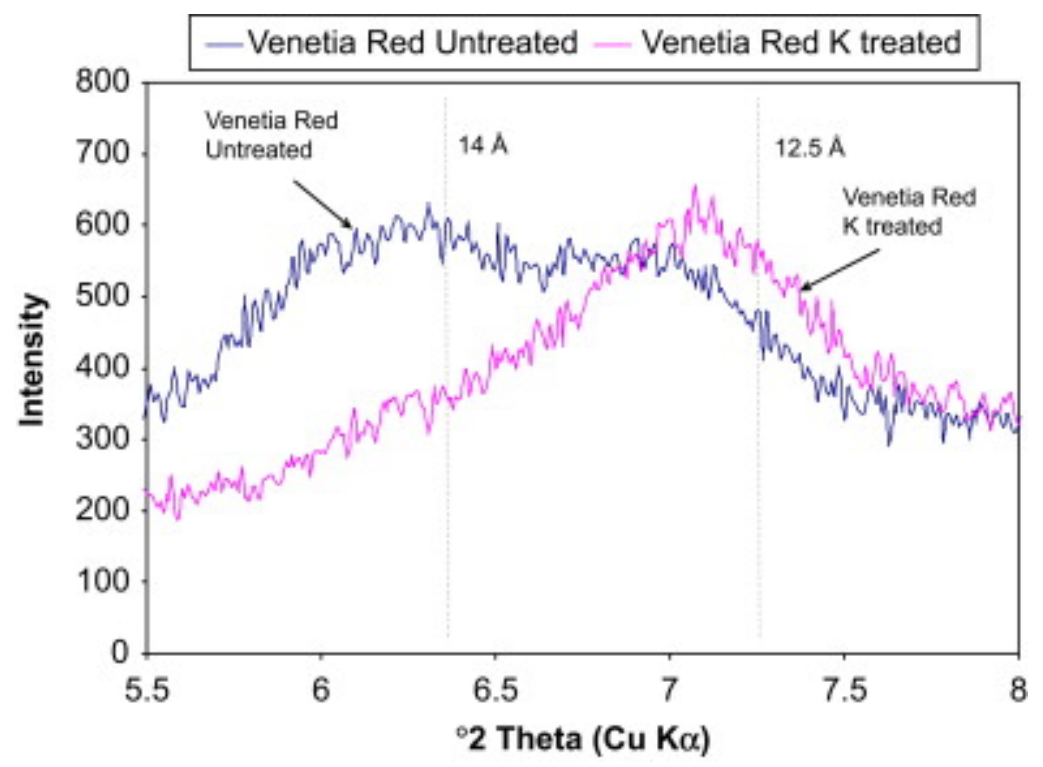

Fig. 8. XRD diffractogram $\left(5.5-8^{\circ} 2 \theta\right)$ displaying the smectite interlayer spacing (dspacing) for untreated Venetia Red and a $1.5 \mathrm{M} \mathrm{KCl}$ treated sample.

\subsection{Adhesion strength tests}

The use of sealants as a means to improve tunnel wall stability is currently being investigated by De Beers. The main function of the liners would be to seal the kimberlitic rock to prevent weathering of underground excavations. The adhesion test measures the adhesive/bond strength of a liner onto a rock substrate. This is a significant property in the design and performance of liner systems. A direct pull test with a glued dolly appears to be the most practical and acceptable method for assessing adhesion as discussed in the standard test (ASTM D4541). A steel disc with a flat contact surface and a suitable shape for connection to the pulling equipment is glued to the surface of the liner and pulled with a tensile stress normal to the rock until de-bonding occurs. The failure stress is calculated by dividing the maximum applied load by the area of the steel disc. Failure does not necessarily occur between the liner and the host rock. Internal failure of the host rock, debonding between the liner and the epoxy, internal failure of the epoxy or the liner and debonding between the steel disc and the epoxy are the alternative modes of failure. The epoxy and the contact between epoxy and liner as well as the contact between epoxy and steel disc are not expected to fail [18]. Internal rock and liner failure are representative of 
the actual in situ interaction between the liner and the rock. Adhesive strength only equals the failure stress if the failure mode is $100 \%$ de-bonding between the rock substrate and the liner, while it will exceed the recorded failure stress in all the other cases.

The adhesion tests were conducted with Cullinan T66N kimberlite samples and were performed by the CSIR-Miningtek (South Africa) in accordance with guidelines as discussed by Kuijpers et al. [19]. Fig. 9 shows the test equipment.

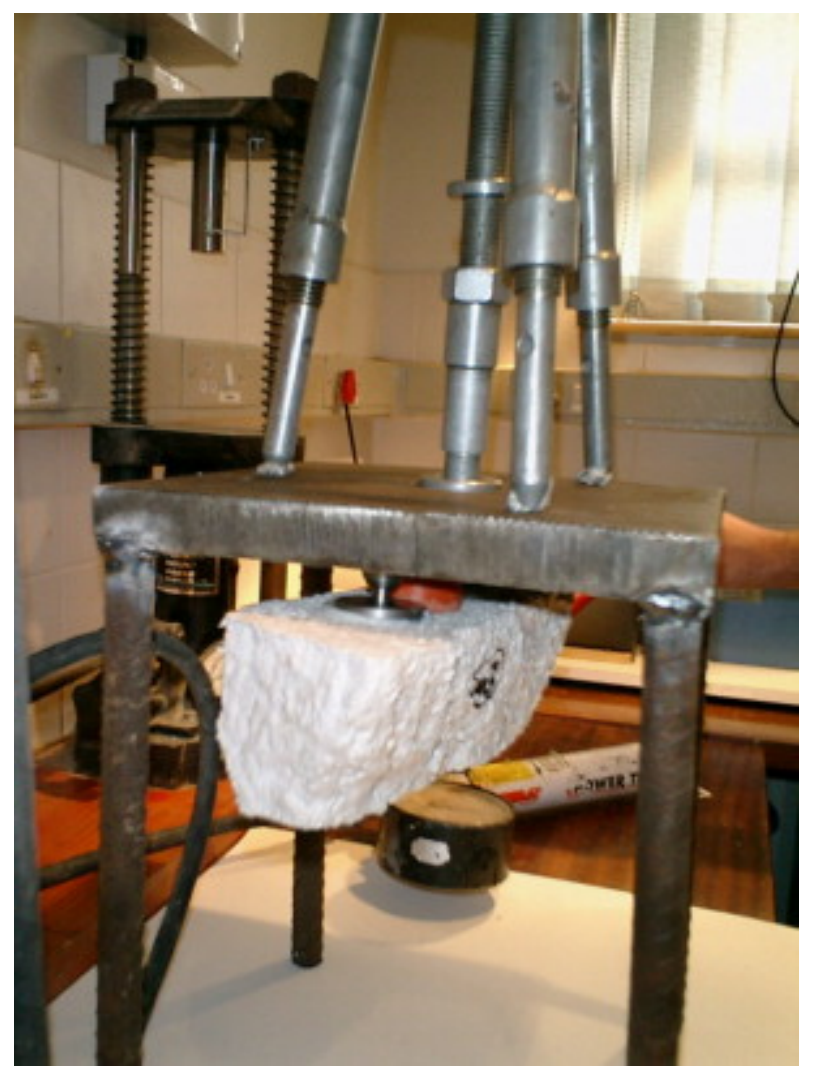

Fig. 9. The CSIR-Miningtek adhesion test unit.

Three different liners were applied to the kimberlite by hand and not sprayed on, as would be the case underground. The thickness was consistent with supplier requirements and allowed to dry for fourteen days. Due to confidentiality agreements between De Beers and the liner producers, product names are not disclosed. Dollies $(39 \mathrm{~mm}$ in diameter) were applied to the liners with a two-component epoxy adhesive (Araldite HY4076 and AV4076) and left to dry for one day before measuring the adhesion strength. Three measurements were taken on each liner to obtain an average value and the type of failure was reported (whether failure occurred only in the contact between liner and kimberlite or within the rock). 
It was found that some liners due to the presence of free water could actually cause weathering of the kimberlite surface (Fig. 10). The effect of $\mathrm{K}^{+}$on the adhesion of three liners was investigated by spraying the kimberlite surface with a $1.5 \mathrm{M} \mathrm{KCl}$ solution and leaving it to dry for $2 \mathrm{~h}$ before applying the liner and following the procedure as discussed earlier. The adhesion of three liners was tested on an untreated and $1.5 \mathrm{M} \mathrm{KCl}$ treated surface. The adhesion test results are shown in Fig. 11.
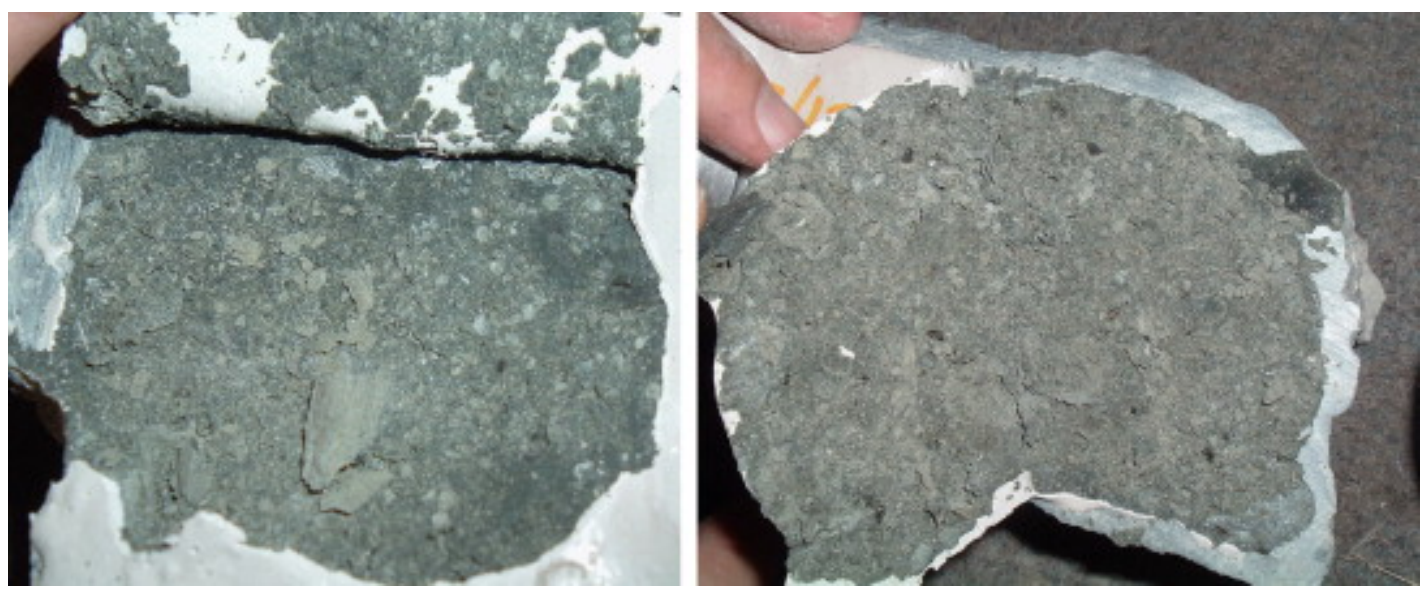

Fig. 10. Weathering of kimberlite due to the liner.

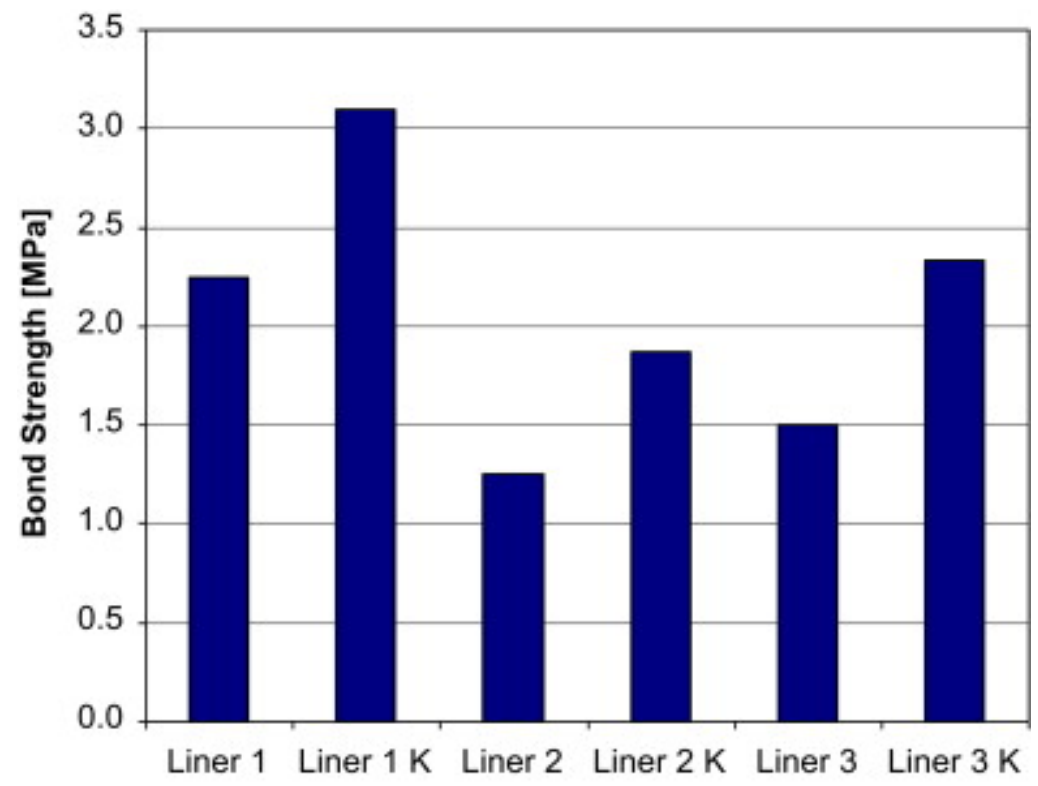

Fig. 11. Adhesion strength test results showing the influence of $\mathrm{K}^{+}$for Cullinan $\mathrm{T} 66 \mathrm{~N}$ treated with three different liners. A $1.5 \mathrm{M} \mathrm{KCl}$ solution was used for pre-treatment of the kimberlite. 
With Liner 1 the $\mathrm{K}^{+}$treated surface showed a $0.9 \mathrm{MPa}$ improvement in adhesion strength compared to a $0.6 \mathrm{MPa}$ improvement with Liner 2 and $0.8 \mathrm{MPa}$ improvement with Liner 3. The improved adhesion by preconditioning the surface with $\mathrm{K}^{+}$is small, but the results show that $\mathrm{K}^{+}$treatment of underground tunnels might improve adhesion of the liner on the kimberlite surface. It was found that the weathering of the rock limits the adhesion of a sealant/liner substantially and that the measured adhesion strength may be a good indication of the degree of weathering on the rock surface.

\section{Conclusions and recommendations}

This report investigates the applicability of different testing methods in evaluating kimberlite weathering and evaluates the efficiency of $\mathrm{K}^{+}$cations in decreasing the weathering of kimberlites.

From the strength measurement techniques (UTB and UCS) both do not represent the weatherability properties of kimberlite adequately; however, it did show a small improvement with $\mathrm{K}^{+}$cations. These strength tests require drill core samples and relatively large numbers of repeated tests to obtain significant results. Treatment in the solutions for longer times (if possible) could also improve the results.

The SDI test proved useful in investigating the weatherability of kimberlite. A strong improvement in the competency of the kimberlite with $\mathrm{K}^{+}$cations is observed with the SDI test. This test requires small lumps for test work, and it is a time consuming test due to wetting and drying cycles.

The PSD is a useful technique in quantifying kimberlite weathering. It is an easy and inexpensive test that can be altered to fit the unique requirements.

The Duncan Free Swelling Test provided good results in assessing kimberlite weatherability. This test showed a strong effect of $\mathrm{K}^{+}$cations and is therefore regarded as a sensitive technique for estimating the swelling/collapsing behaviour of the smectite in the kimberlite. The incorporation of the Duncan Free Swelling coefficient into the geodurability classification renders this technique useful for describing kimberlite weathering. The geodurability classification is a more graphical presentation of the results and classification into the weathering classes is a useful and easy output. The XRD interlayer spacing showed that $\mathrm{K}^{+}$cations collapse the smectite interlayer spacing. It is concluded that $\mathrm{K}^{+}$decreases the weatherability of a kimberlite; this was best reflected in the SDI test and the Duncan Free Swelling Test (also the geodurability classification).

The adhesion strength is an important mechanical property that evaluates the performance of a sealant or liner. For kimberlite, the adhesion test provided additional information on the level of weathering caused by a liner on the rock surface. Treatment of the kimberlite surface with $\mathrm{K}^{+}$improved the adhesion properties of liners. 
This paper shows that $\mathrm{K}^{+}$improves the mechanical properties of kimberlite and can decrease the rate of weathering by collapsing swelling clays. This technique could have value in the taking of drill core samples or in preserving kimberlite samples. It could also be used underground to improve tunnel wall stability. It is important to note that other cations e.g. $\mathrm{Ca}^{2+}$ and $\mathrm{Mg}^{2+}$ have an opposite effect to $\mathrm{K}^{+}$and enhances the weathering of kimberlite by swelling of swelling clays in the presence of water [2]. This technique is therefore not comparable to the current methods used such as lime stabilisation.

\section{References}

[1] R.H. Mitchell, Kimberlites: mineralogy, geochemistry and petrology, Plenum Press, New York (1986).

[2] J. Morkel and M.K.G. Vermaak, The role of swelling clay in kimberlite weathering, Min Proc Extract Metall 115 (2006), pp. 1-5.

[3] J.M. Cases, I. Bérend, M. Francois, J.P. Uriot, L.J. Michot and F. Thomas, Mechanism of adsorption and desorption of water vapour by homoionic montmorillonite: 3. The $\mathrm{Mg}^{2+}, \mathrm{Ca}^{2+}, \mathrm{Sr}^{2+}$ and $\mathrm{Ba}^{2+}$ exchanged forms, Clays Clay Min 45 (1997), pp. 8-22.

[4] M. El-Batouti, O.M. Sadek and F.F. Assaad, Kinetics and thermodynamics studies of copper exchange on Na-montmorillonite clay mineral, J Colloid Interf Sci 259 (2003), pp. 223-227.

[5] G. Rytwo, A. Banin and S. Nir, Exchange reactions in the $\mathrm{Ca}-\mathrm{Mg}-\mathrm{Na}$ montmorillonite system, Clay Min 44 (1996), pp. 276-285.

[6] R. Prost, Near infrared properties of water in Na-hectorite pastes, International clay conference, developments in sedimentology vol. 35, Elsevier, Amsterdam (1981).

[7] A. Czimerova, L. Jankovic and J. Bujdak, Effect of the exchangeable cations on the spectral properties of methylene blue in clay dispersions, J Colloid Interf Sci 274 (2004), pp. 126-132.

[8] R. Badreddine, R. Le Dred and R. Prost, Far infrared study of $\mathrm{K}^{+}, \mathrm{Rb}^{+}$and $\mathrm{Cs}^{+}$during their exchange with $\mathrm{Na}^{+}$and $\mathrm{Ca}^{2+}$ in vermiculite, Clay Miner 37 (2002), pp. 71-81.

[9] C.D. Carson and J.B. Dixon, Potassium selectivity in certain montmorillonitic soil clays, Soil Sci Soc Am Proc 36 (1972), pp. 838-843.

[10] C. Gökçeoglu, R. Ulusay and H. Sönmez, Factors affecting the durability of selected weak and clay-bearing rocks from Turkey, with particular emphasis on the influence of the number of drying and wetting cycles, Eng Geol 57 (2000), pp. 215-237. 
[11] International Society of Rock Mechanics Commission on Standardisation of laboratory and field tests. Int J Rock Mech Min Sci 1978; 15: 99-121.

[12] F.T. Madsen, International Society of Rock Mechanics Commission on Swelling rocks and commission on testing methods, Int J Rock Mech Min Sci 36 (1999), pp. 291306.

[13] H.J. Olivier, A new engineering-geological rock durability classification, Eng Geol 14 (1979), pp. 255-279.

[14] R.E. Grim, Clay mineralogy, McGraw-Hill, New York (1968).

[15] D. Tessier, N. Saiyouri and P.Y. Hicher, Experimental study of swelling in unsaturated compacted clays, Clay Miner 39 (2004), pp. 469-479.

[16] Malla PB, Douglas LA. Identification of expanding layer silicates: layer charge vs. expansion properties. In: Proceedings of the international clay conference, Denver, 1985.

[17] E. Ferrage, B. Lanson, B.A. Sakharov and V.A. Drits, Investigation of smectite hydration properties by modeling experimental X-ray diffraction patters: part I. Montmorillonite hydration properties, Am Mineral 90 (2005), pp. 1358-1374.

[18] Saydam S, Docrat Y. Evaluating the adhesion strength of different sealants on kimberlite. In: Proceedings of the 11th congress of international society of rock mechanics, Lisbon. London: Taylor \& Francis; 2007. p. 585-8.

[19] Kuijpers JS, Sellers EJ, Toper AZ, Rangasamy T, Ward T, Van Rensburg AJ, et al. Required technical specifications and standard testing methodology for thin sprayed linings. SIMRAC project SIM 020206; 2004. 